\title{
Assessment of Duration of Staying Free from Acquiring Rehappening Opportunistic Infections among Pre-ART People Living with HIV/AIDS between 2008 and 2013
}

\author{
Habtamu Mellie Bizuayehu, ${ }^{1}$ Direslgne Misker Abyu, ${ }^{2}$ and Amlaku Mulat Aweke ${ }^{3}$ \\ ${ }^{1}$ Department of Public Health, College of Medicine and Health Science, Debre Markos University, 269 Debre Markos, Ethiopia \\ ${ }^{2}$ Department of Public Health, College of Health Science, Arba Minch University, Arba Minch, Ethiopia \\ ${ }^{3}$ Department of Midwifery, College of Health Science, Mekelle University, Mekelle, Ethiopia \\ Correspondence should be addressed to Habtamu Mellie Bizuayehu; habtamumellie@yahoo.com
}

Received 22 October 2014; Revised 22 December 2014; Accepted 23 December 2014

Academic Editor: Domingo Pere

Copyright (c) 2015 Habtamu Mellie Bizuayehu et al. This is an open access article distributed under the Creative Commons Attribution License, which permits unrestricted use, distribution, and reproduction in any medium, provided the original work is properly cited.

\begin{abstract}
Introduction. In regional state of the study area, HIV (Human Immunodeficiency Virus) prevalence is $2.2 \%$ and opportunistic infections (OIs) occurred in $88.9 \%$ of pre-ART (Antiretroviral Therapy) people living with HIV/AIDS (PLWHA). Even though OIs are prevalent in the study area, duration of staying free from acquiring rehappening opportunistic infections and its determinant factors are not studied. Method. The study was conducted in randomly selected 341 adult Pre-ART PLWHA who are included in chronic HIV care. OI free duration was estimated using the actuarial life table and Kaplan Meier survival. Cox proportionalhazard model was used to calculate hazard rate. Result. OIs were rediagnosed in three quarters (75.37\%) participants. In each week the probability of getting new recurrence OI was about 15.04 per 1000 person weeks. The median duration of not acquiring OI recurrence was 54 weeks. After adjustment, variables associated with recurrence were employment status, marital status, exposure for prophylaxis and adherence to it, CD4 count, and hemoglobin value. Conclusion. Giving prophylaxis and counseling to adhere it, rise in CD4 and hemoglobin level, and enhancing job opportunities should be given for PLWHA who are on chronic HIV care while continuing the care.
\end{abstract}

\section{Introduction}

Globally approximately 34 million people were living with HIV in 2011 [1,2]. Still, there were about 2.2 million new infections [3]. Since the beginning of the epidemic nearly 30 million people have died of AIDS (Acquired Immunodeficiency Syndrome) related causes $[1,2,4]$.

About 22.9 million which is $67 \%$ of those living with HIV/AIDS globally are in Africa though only about $12 \%$ of the world's population lives in the region [2]. In terms of mortality, the region represents about 79\% of AIDS mortality globally [5].

According to 2011 Ethiopian demographic health survey the overall national adult HIV prevalence is $1.5 \%$. The survey showed the HIV prevalence was $2.2 \%$ in Amhara region which is found in North West Ethiopia [6].
Human Immunodeficiency Virus (HIV) infection leads to acquired immunodeficiency syndrome (AIDS) and major causes of morbidity and mortality of such patients are OIs [7]. OIs can occur in up to $40 \%$ of PLWHA with a CD4 count less than 250 cells $/ \mathrm{mm}^{3}$ [8].

A national study in Ethiopia showed HIV patients' had OIs like Herpes Zoster scar (19.3\%), pulmonary tuberculosis (5.2\%), and pneumonia (5.2\%) [9]. The respective prevalence of OIs in pre-ART HIV patients' in two studies in Northwest Ethiopia was $88.9 \%$ [10] and $82.4 \%$ [11].

The problem of HV and OIs is still high in the study area though there is no prior local evidence in the study area thus the current study would give the duration of staying free from acquiring rehappening opportunistic infections after its treatment and its determinant factors. The output of the study will be used to plan resources needed for 
chronic HIV/AIDS care and to know groups of PLWHA given especial attention during care. The evidence is expected to be used by governmental and nongovernmental organizations working on HIV/AIDS or mainstreaming it in order to inform policy makers and medical practitioners.

\section{Methods and Materials}

2.1. Study Setting and Source Population. The study was conducted in Debre Markos town public health institutions among adult Pre-ART PLWHA included to chronic HIV care between 25 March 2008 and 24 March 2013. Debre Markos town is found 299 kilometer away from Addis Ababa (a capital city of Ethiopia) and it has one referral hospital, three public health centers, two NGO clinics, and ten other private clinics and though only the referral hospital and one health center providing chronic HIV care for the HIV/AIDS patients. Thus we conduct a study using retrospective cohort study design on health institutions providing chronic HIV care in the town. The source populations were all adult with age above 17 years PLWHA who had chronic HIV care in the town public health institutions. PLWHA who were having incompletely documented follow up format; not developing OI while registered on HIV chronic care; not taking standard treatment after developing OI according to the Ethiopian Ministry of Health guideline; and pre-ART pregnant or lactating mothers who were taking zidovidine for prevention of mother to child transmission of HIV/AIDS were excluded from the study.

2.2. Sampling and Data Collection Procedure. The sample size was calculated based on the two-sided 95\% confidence interval and 3.5\% margin of error and by using the proportion of pre-ART HIV patients' having OI in Northwest Ethiopia study, which was $88.9 \%$ [10]. The calculated sample size using Open-Epi Version 2.3 May 2009 was 310 then after adding $10 \%$ contingency the final was 341 .

About 2712 PLWHA who fulfill the inclusion criteria were requited from the already available list of PLWHA who were on chronic HIV care in ART clinics. And then selection of participants was made by applying simple random sampling procedure using random number table. The needed data is available on study participants' treatment card and chronic HIV care follow-up form which it is found in the ART clinic but rarely they may seek treatment out-off their follow-up clinic. Thus in order to reduce falsely survival increment, study participants were asked by data collectors about treatment history out of the follow-up health institution and for those doing it, the treatment was checked and abstracted in the respective health institutions. Seeking treatment out of the follow-up health institution was asked when PLWHA come to health institution for follow-up or treatment or by using registered address on follow-up form like phone number or kebele, house number which was used to get to them.

Data collection instrument was developed from federal ministry of health chronic HIV care follow-up form which is used in the ART clinic and also the patient's card. The data was collected by reviewing chronic HIV care follow-up form and patients' card. Among a serious of laboratory measurements (like CD4 count, hemoglobin value, height, and weight) the most nearest to the study period were taken as baseline characteristics. And among the serious measurements performed on PLWHA while she/he is included on the study, the nearest to the OI recurrence or censored was taken as the end line or follow-up values.

Approval of OI free duration was done by reviewing chronic HIV care follow-up form or patient card in ART clinic or out of ART clinic if study participants seek treatment out of ART clinic.

Study participants who start ART/drop-out/loss followup/transferred out/dead by any disease other than OI/cause of death not confirmed while on study or not developing OI at end of the study period were censored. A selected and trained health professionals working in ART clinics in each health institution were used as data collectors and supervisors.

\subsection{Operational Definition}

Survival. Duration of free of OI rehappening.

Censored. Nonrelapse of OI in study participant during follow-up on study, but future relapse is uncertain.

Recurrence/rehappen/relapse: happening or diagnosis of any type of OIs by health personals working in ART clinic after completing the preceding treatment of any type of OI.

Drop Out. If a PLWHA on HIV care lost to follow-up for more than three months as recorded by ART health personnel.

Lost to Follow-Up. If PLWHA on HIV care not seen for equal to or more than one month as recorded by ART health personnel.

Transferred out. If PLWHA on HIV care in one health institution shift to other health institution.

Good Adherence. If PLWHA adherent $\geq 95 \%$ that is the percentage of missed dose is $<2$ doses of 30 doses or $<3$ dose of 60 dose as documented by ART health personnel.

Fair Adherence. If PLHIV adherent $85-94 \%$ that is the percentage of missed dose is 3-5 doses of 30 doses or 3-9 dose of 60 dose as documented by ART health personnel.

Poor Adherence. If PLHIV adherent $<85 \%$ that is the percentage of missed dose is $\geq 6$ doses of 30 doses or $>9$ dose of 60 dose as documented by ART health personnel.

2.4. Data Quality Management and Statistical Analysis. To maintain data quality training was given for data collectors and for supervisors. Properly designed data collection material was developed from Ethiopian federal ministry of health chronic HIV care follow-up form and patients' card. To check correct data collection $10 \%$ of the sample was reabstracted by supervisors. The data were double entered by trained data clerk to check correct data entry. After completing data entry, 
outliers and any missed values were checked using frequency, listing, and sorting and any identified error at any step was corrected by revising the original data abstraction format.

After coding each abstraction format, data was entered in to Epi Info version 3.5.1 statistical package. Analysis of data was done using Open-Epi Version 2.3 May 2009, SPSS version 20, and STATA version 11 statistical packages.

Incidence rate was calculated by dividing total events to person-weeks. OI free duration was estimated using the actuarial life table and Kaplan Meier survival. Assumption of proportional-hazard was checked by Schoenfeld residual with $P$ value $\geq 0.1(\alpha=10 \%)$ and the assumption was not violated. Multicollinearity was checked using Pearson correlation, tolerance/variance inflation factor and there was no colinearity To determine independent predictors of OI free duration cox proportional-hazard model was used to calculate the hazard rate. Variables having $P$ value $<0.05$ at bivariate analysis and not collinear were entered in multivariate cox proportional hazard model to determine the adjusted hazard rate. The cut-off point for significant association was $P$ value 0.05 .

2.5. Ethical Consideration. Ethical approval and clearance was given by School of Public Health Addis Ababa University ethical committee. Permission was also obtained from the concerned bodies of East Gojam zone and Debre Markos town Health Department and the responsible bodies of hospital and health centers. To maintain confidentiality of PLWHA, health professionals working in ART clinic were abstracting the data. In addition no personal identifier was extracted on medical records and the recorded data was not accessed by a third person.

\section{Result}

In the five year study period among 341 study participants, the median duration of follow-up was 41 weeks (95\% CI: 37-47.97) and the minimum, maximum, and interquartile range of follow-up was 1, 234, 50 weeks, respectively. Among the study participants majority of them were females 234 (68.6\%), orthodox Christian 316 (92.7\%), living in urban 229 (67.2\%), not educated 153 (44.9\%), married 130 (38.1\%), and not employed in governmental or private organizations 291 $(85.3 \%)$. Their mean age was $33.3( \pm 10.6)$ years, in which almost all of them were below 50 years old 318 (93.3\%) (Table 3).

3.1. The Baseline and Follow-Up Laboratory, Clinical and Prophylaxis Characteristics. At base line, the median values for CD4 count (cells/uL) and hemoglobin value (g/dl) were 383 and 11.6, respectively and the respective end line values were 382.5 and 12.5. The base line and end line body mass index mean values were $19.1( \pm 3.1)$ and $19.7( \pm 3.1)$ kilogram per meter square units, respectively.

At start of the study, majority of participants were having WHO stage II OI 165 (48.4\%). About 11 (3.2\%) participants were having concomitant chronic diseases like hypertension,

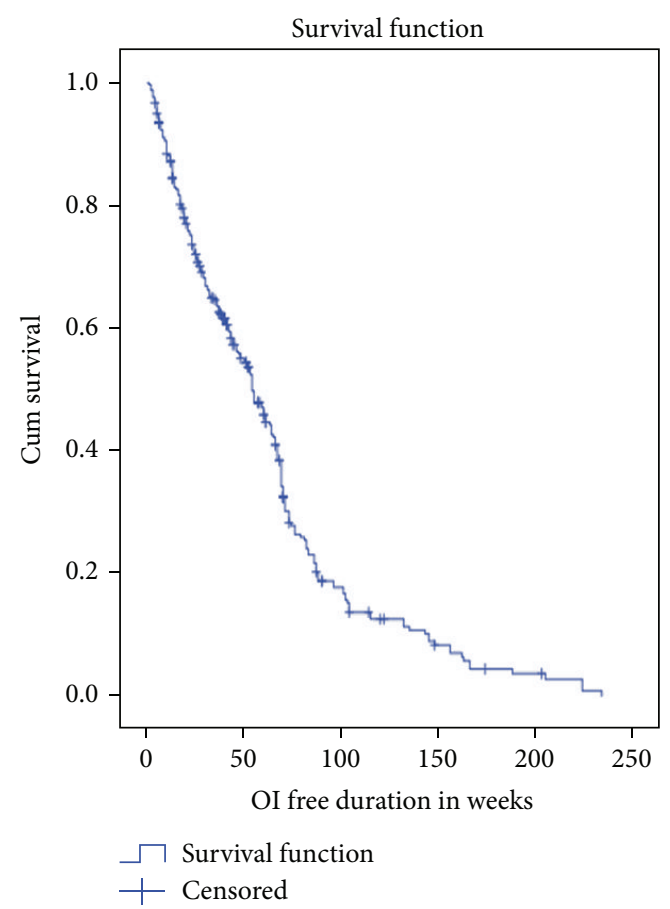

FIGURE 1: Kaplan-Meier survival estimation of progressing to OI rediagnosing among pre-ART PLWHA in Debre Markos town between 2008 and 2013.

cardiac disease, and diabetes mellitus. With regard to functional status, almost all of them were working both at base line 83 (83\%) and at end line 297 (87.1\%) (Table 3).

About three quarters of participants were taking prophylaxis both at base line $244(71.6 \%)$ and at follow-up $255(74.8 \%)$ and almost all of them were having good drug adherence both at base line $225(92.2 \%)$ and at followup $231(90.6 \%)$ in which nearly all of them were taking cotrimoxazole both at base line 225 (92.2\%) and at follow-up 243 (95.3\%) (Table 3).

3.2. Incidence of Recurrence and OI Free Duration. The cumulative incidence of OI recurrence was 75.37\% (95 CI: 70.679.7\%) and incidence rate was 15.04 (95 CI: 13.1-16.97\%) per 1000 person weeks. Of recurrence OIs, about 12.8\% (95 CI: 9.16-17.36\%) were self-relapsed and incidence rate of selfrelapse was 1.93 (95 CI: 1.35-2.68\%) per 1000 person weeks. The most rediagnosed OI was recurrent upper respiratory tract infection 44 (17.1\%) whereas chronic diarrhea was most self-relapsed OI (23.7\%) (Table 1).

According to the Kaplan-Meier survival estimation, the median duration of not acquiring OI recurrence was 54 weeks (95\% CI: 46.9-61.1) (Figure 1). Among participants, those employed were more surviving than unemployed (Figure 2). As the actuarial life table analysis showed about $91 \%$ participants were not acquiring $\mathrm{OI}$ at end of 10 weeks and the probability of free of OI recurrence at end of 220 and 230 weeks was about $1 \%$ and $<0.01 \%$, respectively (Table 2 ).

In bivariate cox proportional hazard model, the predictor variables that showed significant $(P<0.05)$ association with 
TABLE 1: The rediagnosed OIs of any type and self-relapse among participants' in Debre Markos town between 2008 and 2013.

\begin{tabular}{|c|c|c|c|}
\hline \multirow{2}{*}{ Rediagnosed OI } & \multirow{2}{*}{ Frequency of overall rediagnosis (\%) } & \multicolumn{2}{|c|}{ Self-relapse } \\
\hline & & Yes $(\%)$ & No $(\%)$ \\
\hline Recurrent upper respiratory tract infection & $44(17.1)$ & $9(20.5)$ & $35(79.5)$ \\
\hline Chronic diarrhea & $38(14.8)$ & $9(23.7)$ & $29(76.3)$ \\
\hline Oral candidacies & $25(9.7)$ & $1(4)$ & $24(96)$ \\
\hline Pneumonia & $25(9.7)$ & $4(16)$ & $21(84)$ \\
\hline Herpes Zoster & $24(9.3)$ & $3(12.5)$ & $21(87.5)$ \\
\hline Extra pulmonary tuberculosis & $24(9.3)$ & $1(4.2)$ & $23(95.8)$ \\
\hline Minor mucocutanous manifestation & $15(5.8)$ & $2(13.3)$ & $13(86.7)$ \\
\hline Wasting syndrome & $9(3.5)$ & $2(22.2)$ & $7(77.8)$ \\
\hline Persistent generalized lymphadenopathy & $8(3.1)$ & $1(12.5)$ & $7(87.5)$ \\
\hline Viral infection & $6(2.3)$ & $1(16.7)$ & $5(83.3)$ \\
\hline Others & $39(15.2)$ & 0 & $39(100)$ \\
\hline Total & $257(100)$ & 33 (12.8) & 224 (87.2) \\
\hline
\end{tabular}

TABLE 2: The actuarial life table estimation of participants' duration of diagnosing of rehappening OI in Debre Markos town between 2008 and 2013.

\begin{tabular}{|c|c|c|c|c|c|c|}
\hline $\begin{array}{l}\text { Interval start } \\
\text { time }\end{array}$ & $\begin{array}{c}\text { Number } \\
\text { entering interval }\end{array}$ & $\begin{array}{c}\text { Number } \\
\text { withdrawing } \\
\text { during interval } \\
\end{array}$ & $\begin{array}{c}\text { Number } \\
\text { exposed to risk }\end{array}$ & $\begin{array}{c}\text { Number of OIs } \\
\text { diagnosed at } \\
\text { interval }\end{array}$ & $\begin{array}{c}\text { Cumulative } \\
\text { proportion surviving } \\
\text { at end of interval }\end{array}$ & Hazard rate \\
\hline 0 & 341 & 7 & 337.5 & 32 & 0.91 & 0.01 \\
\hline 10 & 302 & 11 & 296.5 & 41 & 0.78 & 0.01 \\
\hline 20 & 250 & 9 & 245.5 & 31 & 0.68 & 0.01 \\
\hline 30 & 210 & 11 & 204.5 & 20 & 0.61 & 0.01 \\
\hline 40 & 179 & 11 & 173.5 & 18 & 0.55 & 0.01 \\
\hline 50 & 150 & 10 & 145.0 & 21 & 0.47 & 0.02 \\
\hline 60 & 119 & 8 & 115.0 & 31 & 0.34 & 0.03 \\
\hline 70 & 80 & 7 & 76.5 & 18 & 0.26 & 0.03 \\
\hline 80 & 55 & 1 & 54.5 & 15 & 0.19 & 0.03 \\
\hline 90 & 39 & 2 & 38.0 & 2 & 0.18 & 0.01 \\
\hline 100 & 35 & 1 & 34.5 & 8 & 0.14 & 0.03 \\
\hline 110 & 26 & 1 & 25.5 & 2 & 0.13 & 0.01 \\
\hline 120 & 23 & 2 & 22.0 & 0 & 0.13 & 0.00 \\
\hline 130 & 21 & 0 & 21.0 & 3 & 0.11 & 0.02 \\
\hline 140 & 18 & 1 & 17.5 & 4 & 0.08 & 0.03 \\
\hline 150 & 13 & 0 & 13.0 & 2 & 0.07 & 0.02 \\
\hline 160 & 11 & 0 & 11.0 & 4 & 0.05 & 0.04 \\
\hline 170 & 7 & 1 & 6.5 & 0 & 0.05 & 0.00 \\
\hline 180 & 6 & 0 & 6.0 & 1 & 0.04 & 0.02 \\
\hline 190 & 5 & 0 & 5.0 & 0 & 0.04 & 0.00 \\
\hline 200 & 5 & 1 & 4.5 & 1 & 0.03 & 0.02 \\
\hline 210 & 3 & 0 & 3.0 & 0 & 0.03 & 0.00 \\
\hline 220 & 3 & 0 & 3.0 & 2 & 0.01 & 0.10 \\
\hline 230 & 1 & 0 & 1.0 & 1 & 0.00 & 0.20 \\
\hline
\end{tabular}

the outcome variable were marital status, occupational status, educational status, the base line and follow-up functional status, having exposure for prophylaxis at baseline and adhering to it both at baseline and at follow up, baseline hemoglobin value, follow-up CD4 count, follow-up body mass index, number of OIs diagnosed at one time at start of the study, and being diagnosed wasting syndrome and Herpes Zoster at start of study (Table 3).

After adjustment for potential confounders in multivariate cox proportional hazard model, the significant $(P<0.05)$ 
TABLE 3: The cumulative incidence of diagnosing OI, Kaplan Meier estimation of median duration of not acquiring OI recurrence and cox proportional hazard model of the association between characteristics and OI recurrence among PLWHA in Debre Markos town between 2007 and 2013.

\begin{tabular}{|c|c|c|c|c|c|}
\hline \multirow{2}{*}{ Variables } & \multicolumn{2}{|c|}{ Diagnosis of recurrence OI } & \multirow{2}{*}{ Median KMS } & \multirow{2}{*}{ CHR (95\% CI) } & \multirow{2}{*}{ AHR (95\% CI) } \\
\hline & Yes (\%) & No $(\%)$ & & & \\
\hline \multicolumn{6}{|l|}{ Marital status } \\
\hline Married & $101(39.3)$ & $29(34.5)$ & 60 & 1 & 1 \\
\hline Single & $68(26.5)$ & $11(13.1)$ & 46 & $1.65(1.21-2.26)$ & $1.19(0.72-1.96)$ \\
\hline Divorced & $60(23.3)$ & $32(38.1)$ & 64 & $1.02(0.74-1.41)$ & $0.57(0.33-0.99)$ \\
\hline Widowed & $28(10.9)$ & $12(14.3)$ & 42 & $1.69(1.10-2.59)$ & $1.64(0.79-3.40)$ \\
\hline \multicolumn{6}{|l|}{ Educational status } \\
\hline Not educated & $110(42.8)$ & $43(51.2)$ & 55 & 1 & 1 \\
\hline Grades 1-8 & $82(31.9)$ & $16(19)$ & 41 & $1.06(0.79-1.41)$ & $1.17(0.70-1.94)$ \\
\hline Grades 9-12 & $44(17.1)$ & $14(16.7)$ & 55 & $0.84(0.59-1.19)$ & $1.38(0.71-2.68)$ \\
\hline Above grade 12 & $21(8.2)$ & $11(13.1)$ & 67 & $0.49(0.30-0.80)$ & $1.55(0.69-3.47)$ \\
\hline \multicolumn{6}{|l|}{ Occupational status } \\
\hline Unemployed & $221(86)$ & $70(83.3)$ & 53 & 1 & 1 \\
\hline Employed & $36(14)$ & $14(16.7)$ & 76 & $0.48(0.33-0.69)$ & $0.34(0.16-0.71)$ \\
\hline \multicolumn{6}{|l|}{ Functional status ${ }^{\mathrm{B}}$} \\
\hline Working & $206(80.2)$ & $77(91.7)$ & 60 & 1 & 1 \\
\hline Ambulatory/bed-ridden & $51(19.8)$ & $7(8.3)$ & 32 & $1.7(1.25-2.32)$ & $1.59(0.81-3.12)$ \\
\hline \multicolumn{6}{|l|}{ Functional status ${ }^{\mathrm{E}}$} \\
\hline Working & $215(83.7)$ & $82(97.6)$ & 60 & 1 & 1 \\
\hline Ambulatory/bed-ridden & $42(16.3)$ & $2(2.4)$ & 37 & $1.65(1.17-2.31)$ & $0.97(0.52-1.81)$ \\
\hline \multicolumn{6}{|c|}{ Number of OIs treated at base line } \\
\hline 1 & $203(79)$ & $62(73.8)$ & 59 & 1 & 1 \\
\hline$\geq 2$ & $54(21)$ & $22(26.2)$ & 44 & $1.38(1.01-1.87)$ & $1.19(0.69-2.07)$ \\
\hline \multicolumn{6}{|l|}{ Prophylaxis adherence $\mathrm{e}^{\mathrm{B} .}$} \\
\hline Good & $170(91.4)$ & $55(94.8)$ & 64 & 1 & 1 \\
\hline Fair & $6(3.2)$ & $0(0)$ & 43 & $2.69(1.19-6.13)$ & $14.92(1.03-215)$ \\
\hline Poor & $10(5.4)$ & $3(5.2)$ & 23 & $1.76(0.92-3.35)$ & $5.96(1.21-29.41)$ \\
\hline \multicolumn{6}{|l|}{ Prophylaxis adherence ${ }^{\mathrm{F}}$} \\
\hline Good & $173(88.3)$ & $58(98.3)$ & 64 & 1 & 1 \\
\hline Fair & $9(4.6)$ & $0(0)$ & 55 & $1.06(0.54-2.08)$ & $5.39(1.77-16.36)$ \\
\hline Poor & $14(7.1)$ & $1(1.7)$ & 22 & $2.2(1.27-3.82)$ & $5.79(1.86-17.98)$ \\
\hline \multicolumn{6}{|l|}{ Prophylaxis exposure ${ }^{\mathrm{B} .}$} \\
\hline No & $71(27.6)$ & $26(31)$ & 37 & 1 & 1 \\
\hline Yes & $186(72.4)$ & $58(69)$ & 63 & $0.64(0.49-0.85)$ & $0.31(0.19-0.49)$ \\
\hline \multicolumn{6}{|l|}{ CD 4 count $(\text { cells } / \mu \mathrm{L})^{\mathrm{F}}$} \\
\hline$\leq 100$ & $4(2.2)$ & $1(1.4)$ & 17 & 1 & 1 \\
\hline 101-199 & $19(10.6)$ & $3(4.2)$ & 60 & $0.19(0.06-0.58)$ & $0.12(0.029-0.49)$ \\
\hline $200-350$ & $50(27.8)$ & $27(37.5)$ & 69 & $0.14(0.048-0.39)$ & $0.21(0.057-0.79)$ \\
\hline $351-499$ & $58(32.2)$ & $24(33.3)$ & 66 & $0.17(0.058-0.47)$ & $0.16(0.045-0.59)$ \\
\hline$\geq 500$ & $49(27.2)$ & $17(23.6)$ & 70 & $0.13(0.046-0.38)$ & $0.17(0.46-0.62)$ \\
\hline \multicolumn{6}{|l|}{ Hemoglobin value $(\mathrm{g} / \mathrm{dL})^{\mathrm{B} .}$} \\
\hline$<10$ & $61(31.1)$ & $5(16.7)$ & 26 & 1 & 1 \\
\hline$\geq 10$ & $135(68.9)$ & $25(83.3)$ & 53 & $0.55(0.40-0.75)$ & $0.49(0.25-0.97)$ \\
\hline
\end{tabular}


TABLE 3: Continued.

\begin{tabular}{|c|c|c|c|c|c|}
\hline \multirow{2}{*}{ Variables } & \multicolumn{2}{|c|}{ Diagnosis of recurrence OI } & \multirow{2}{*}{ Median KMS } & \multirow{2}{*}{ CHR (95\% CI) } & \multirow{2}{*}{$\operatorname{AHR}(95 \% \mathrm{CI})$} \\
\hline & Yes (\%) & No $(\%)$ & & & \\
\hline \multicolumn{6}{|c|}{ Body mass index $\left(\mathrm{kg} / \mathrm{m}^{2}\right)^{\mathrm{F}}$} \\
\hline$\leq 18.4$ & $122(47.7)$ & $36(42.9)$ & 46 & 1 & 1 \\
\hline $18.5-22.9$ & $103(40.2)$ & 35 (41.7) & 54 & $0.93(0.71-1.21)$ & $0.89(0.54-1.46)$ \\
\hline$\geq 23$ & $31(12.1)$ & $13(15.5)$ & 69 & $0.54(0.37-0.79)$ & $0.61(0.33-1.14)$ \\
\hline \multicolumn{6}{|c|}{ Herpes Zoster diagnosis ${ }^{\mathrm{B} .}$} \\
\hline No & $202(78.6)$ & $73(86.9)$ & 55 & 1 & 1 \\
\hline Yes & $55(21.4)$ & $11(13.1)$ & 48 & $1.38(1.02-1.86)$ & $1.18(0.65-2.13)$ \\
\hline \multicolumn{6}{|c|}{ Wasting syndrome diagnosis ${ }^{\mathrm{B}}$} \\
\hline No & $247(96.1)$ & $84(100)$ & 55 & 1 & 1 \\
\hline Yes & $10(3.9)$ & $0(0)$ & 23 & $2.39(1.21-4.34)$ & $1.29(0.36-4.71)$ \\
\hline \multicolumn{6}{|c|}{$\begin{array}{l}\text { B Base line value. } \\
\text { FFollow-up value. } \\
\text { KMS: Kaplan Meier survival in weeks. } \\
\text { CHR: crude hazard rate. } \\
\text { AHR: Adjusted hazard rate. }\end{array}$} \\
\hline
\end{tabular}

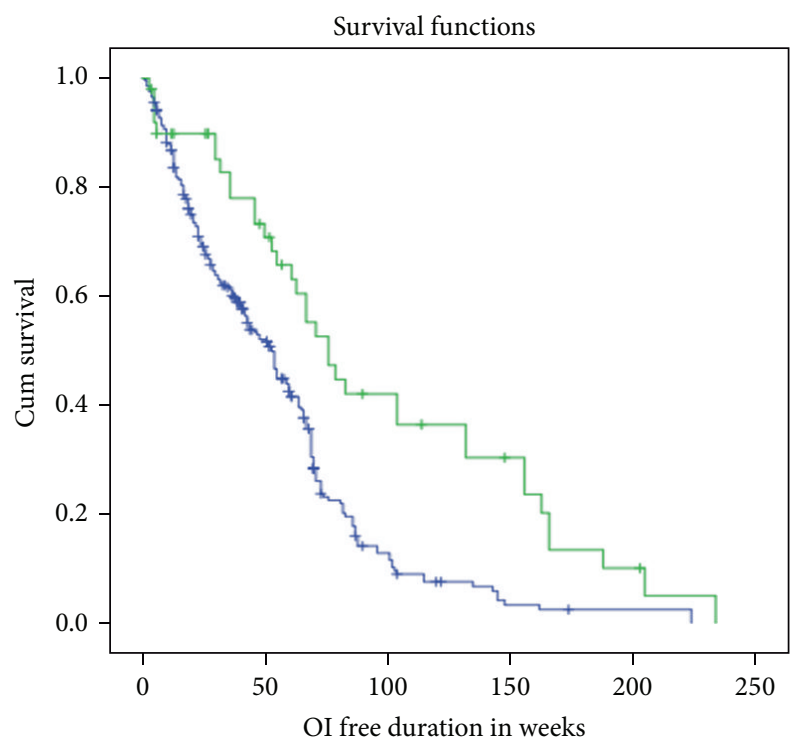

Occupational status

$\begin{array}{ll}\neg \text { Unemployed } & + \text { Unemployed-censored } \\ \neg \text { Employed } & + \text { Employed-censored }\end{array}$

Figure 2: Kaplan-Meier survival estimation of progressing to acquiring OI recurrence among employed and unemployed preART PLWHA in Debre Markos town between 2008 and 2013.

predictors preventing repeated diagnosing of OI rediagnosis were being employed in governmental or private sectors, divorced than married, taking prophylaxis at baseline, having a follow-up CD4 count above 100 cells/ $\mu \mathrm{L}$, and having hemoglobin value of $10 \mathrm{~g} / \mathrm{dl}$ and above, whereas not adhering to prophylaxis both at base line and at follow-up was the risk factors for short time rediagnosing of OIs (Table 3).

\section{Discussion}

In the five-year study period, the cumulative incidence of $\mathrm{OI}$ recurrence was seen in about three quarters (75.37\%) of participants. Different studies have diverse figures with regard to the proportion of OI. In North India, tuberculosis was the commonest OI (71\%) followed by candidiasis (39.3\%), PCP (7.4\%), cryptococcal meningitis, and cerebral toxoplasmosis (3.7\% each) [12]. In the same country of southern India, proportion of pulmonary tuberculosis was (14\%) [13]. A national study in Ethiopia showed HIV patients' had OIs like Herpes Zoster scar (19.3\%), pulmonary tuberculosis (5.2\%), and pneumonia (5.2\%) [9]. In Northwest Ethiopia, about $88.9 \%$ pre-ART HIV patients had OIs [10]. Another study in similar area also showed that $82.4 \%$ pre-ART HIV patients have OIs [11]. The respective prevalence of pulmonary tuberculosis and cryptococcal meningitis among PLWHA in North West Ethiopia was about 7.5\% [14] and 8.3\% [15]. In about a quarter (22.7\%) of PLWHA, chronic diarrhea was seen in Southern Ethiopia [16]. The cumulative incidence of recurrent OIs like recurrent upper respiratory tract infection, chronic diarrhea, bacterial pneumonia, oral candidiasis, herpes zoster, extra pulmonary tuberculosis, PCP, and pulmonary tuberculosis in current study was $17.1 \%, 14.8 \%, 9.8 \%, 9.8 \%, 9.3 \%, 9.3 \%$, and $7 \%, 5.4 \%$, respectively, and this finding is relatively in line with some figures of OIs in the studies $[9,10,12-14]$ though it is lower than some other studies $[11,15,16]$. The possible reasons for discrepancy would be different in study design (the prior ones that are cross-sectional), study population (prior ones using PLWHA when coming to initiate ART which will increase the prevalence since ART is initiated using WHO stage of disease and CD4 count), study area, and other sociocultural practices.

In this study, chronic diarrhea was most self-relapsed OI (23.7\%) and this might be attributed by not using improved 
drinking water source and sanitation facility since only $50.8 \%$ and $8.8 \%$ of Ethiopians were using improved drinking water source and sanitation facility according to 2011 Ethiopian demographic health survey [6].

The current finding of being employed in governmental or private sectors as increasing duration of frequent vising of health institutions due to illness of rehappened OIs was in harmony with a cohort study in United States [17].

The current study that comes up as having a follow-up CD 4 count above 100 cells $/ \mu \mathrm{L}$ compared to $\leq 100$ cells $/ \mu \mathrm{L}$ was preventing repeated diagnosing of OI recurrence and this is in agreement with other studies [18-22]. The HIV cohort study in Switzerland showed that CD4 count is one of the predictor for OI progression; a rise in CD4 count by $50 \times 10^{6} / \mathrm{L}$ or more by 6 months reduced subsequent OIs with hazard ratio of 0.32 [19]. Another cohort study also showed that higher CD4 cell count was associated with a reduction of risk of new OI progression and with a hazard ratio compared to 100 cells $/ \mathrm{mL}$ of 0.35 for counts 200 cells $/ \mathrm{mL}, 0.81$ for counts 200 to 350 cells $/ \mathrm{mL}, 0.74$ for counts 350 to 500 cells $/ \mathrm{mL}$, and 0.96 for counts 500 cells/mL or above [22].

In this study, taking prophylaxis at baseline was enhancing duration of frequent diagnosis of recurrent $\mathrm{OI}$ and the finding was supported by other studies [23-26]. Primary prophylaxis with trimethoprim-sulfamethoxazole is preventing life-threatening OIs like PCP, toxoplasmosis, and bacterial infections [23]. Taking cotrimoxazole reduces the risk of PCP and tuberculosis [24]. Taking cotrimoxazole prophylaxis was preventing OIs like diarrhea in an experimental study in Ugandan PLHIV adults [25]. The evidence of preventing OIs like PCP using Cotrimoxazole was also assured in an experimental study [26].

\section{Conclusion and Recommendation}

During the historical follow-up period, OIs were rediagnosed in about three quarters $(75.37 \%)$ of participants. Of rediagnosed OIS, nearly one every ten rediagnosis was selfrelapsed $(12.8 \%)$. In each week the probability of getting new recurrence of any type OI and self-relapse OI was about 15.04 and 1.93 per 1000 person weeks, respectively. Commonly rehappening OIs were recurrent upper respiratory tract infection $(17.1 \%)$, chronic diarrhea $(14.8 \%)$, bacterial pneumonia $(9.8 \%)$, oral candidiasis $(9.8 \%)$, Herpes Zoster $(9.3 \%)$, and extra pulmonary tuberculosis (9.3\%).

According to the Kaplan-Meier survival estimation, the median duration of not acquiring OI recurrence was 54 weeks. After adjustment for potential confounders in multivariate cox proportional hazard model, the significant $(P<0.05)$ predictors preventing repeated diagnosing of OI recurrence were being employed in governmental or private sectors, divorced than married, taking prophylaxis at baseline, having a follow-up CD4 count above 100 cells $/ \mu \mathrm{L}$ and having hemoglobin value of $10 \mathrm{~g} / \mathrm{dL}$ and above, whereas not adhering to prophylaxis both at base line and at followup was the risk factors for frequent diagnosing of OI recurrence.
5.1. Based on This Study Finding, the Following Recommendations Can Be Forwarded

(i) Providing prophylaxis and counseling to adhere to it should be further enhanced.

(ii) Treatment and other sportive measures should be given to enhance the CD4 count and hemoglobin value.

(iii) During giving of HIV chronic care especial attention should be given for those not adhering to prophylaxis drug since they have OI recurrence in short periods.

(iv) Governmental or nongovernmental organizations should give especial criteria that support PLWHA to win in computation of job at vacancies since being employed reduces duration repeated rediagnosing of OI.

(v) Finally we recommend further observational studies with prospective design to ascertain the current findings.

\section{Conflict of Interests}

The authors declare that there is no conflict of interests regarding the publication of this paper.

\section{Acknowledgments}

The authors would like thank Professor Mitkie Getnet, Dr. Worku Alemayehu, and Dr. Enquselassie Fikre, Addis Ababa University, Debre Markos town health managers, ART clinic staffs, for their contribution in the success of the work.

\section{References}

[1] U.S. Global health policy fact sheet, the Global HIV/AIDS Epidemic, November 2011.

[2] Global HIV/AIDS Response-Epidemic update and health sector progress towards Universal Access-Progress Report 2011.

[3] Joint United Nations Programme on HIV/AIDS, Together We Will End AIDS, Joint United Nations Programme on HIV/AIDS, Geneva, Switzerland, 2012.

[4] UNAIDS World AIDS Day report, Regional Fact Sheet 2012.

[5] E. J. Mills, J. B. Nachega, I. Buchan et al., "Adherence to antiretroviral therapy in sub-Saharan Africa and North America: a meta-analysis," Journal of the American Medical Association, vol. 296, no. 6, pp. 679-690, 2006.

[6] Central Statistical Agency (CSA), Ethiopia Demographic and Health Survey 2011; Final Draft Report, Central Statistical Agency, Addis Ababa, Ethiopia; ICF International, Calverton, Md, USA, 2012.

[7] Z. T. Mariam, G. Abebe, and A. Mulu, "Opportunistic and other intestinal parasitic infections in AIDS patients, HIV seropositive healthy carriers and HIV seronegative individuals in southwest Ethiopia," East African Journal of Public Health, vol. 5, no. 3, pp. 169-173, 2008.

[8] J. E. Gallant, R. D. Moore, and R. E. Chaisson, "Prophylaxis for opportunistic infections in patients with HIV infection," Annals of Internal Medicine, vol. 120, no. 11, pp. 932-944, 1994. 
[9] T. Berhe, Y. Melkamu, and A. Amare, "The pattern and predictors of mortality of HIV/AIDS patients with neurologic manifestation in Ethiopia: a retrospective study," AIDS Research \& Therapy, vol. 9, article 11, 2012.

[10] A. Bayeh, T. Tewabe, A. Alem, and M. Yessin, "ART-naive HIV patients at Feleg-Hiwot Referral Hospital Northwest Ethiopia," The Ethiopian Journal of Health Development, vol. 24, no. 1, pp. 3-8, 2010

[11] N. T. Wabe and M. Alemu, "Immunological and clinical progress of HIV-infected patients on highly active antiretroviral therapy in north west Ethiopia," Gaziantep Medical Journal, vol. 18, no. 1, pp. 31-36, 2012.

[12] S. K. Sharma, T. Kadhiravan, A. Banga, T. Goyal, I. Bhatia, and P. K. Saha, "Spectrum of clinical disease in a series of 135 hospitalised HIV-infected patients from north India," BMC Infectious Diseases, vol. 4, article 52, 2004.

[13] N. Kumarasamy and B. Devaleenol, "Factors associated with mortality among HIV-infected patients in the era of highly active antiretroviral therapy in southern India," Journal of Infectious Diseases, vol. 14, no. 2, pp. e127-e131, 2010.

[14] Y. Wondimeneh, D. Muluye, and Y. Belyhun, "Prevalence of Pulmonary tuberculosis and immunological profile of HIV coinfected patients in Northwest Ethiopia," BMC Research Notes, vol. 5, article 331, 2012.

[15] T. Seboxa, S. Alemu, A. Assefa, A. Asefa, and E. Diro, "Cryptococcal meningitis in patients with acquired immunudeficiency syndrome in prehaart era at Gondar College of Medical Sciences Hospital north-west Ethiopia," Ethiopian Medical Journal, vol. 48, no. 3, pp. 237-241, 2010.

[16] S. Assefa, B. Erko, G. Medhin, Z. Assefa, and T. Shimelis, "Intestinal parasitic infections in relation to HIV/AIDS status, diarrhea and CD4 T-cell count," BMC Infectious Diseases, vol. 9, article 155, 2009.

[17] P. Patel, T. Bush, K. H. Mayer et al., "Prevalence and risk factors associated with herpes simplex virus- 2 infection in a contemporary cohort of HIV-infected persons in the united states," Sexually Transmitted Diseases, vol. 39, no. 2, pp. 154-160, 2012.

[18] A. Antinori, D. Larussa, A. Cingolani et al., "Prevalence, associated factors, and prognostic determinants of AIDS-related toxoplasmic encephalitis in the era of advanced highly active antiretroviral therapy," Clinical Infectious Diseases, vol. 39, no. 11, pp. 1681-1691, 2004.

[19] B. Ledergerber, M. Egger, V. Erard et al., "AIDS-related opportunistic illnesses occurring after initiation of potent antiretroviral therapy: the Swiss HIV cohort study," Journal of the American Medical Association, vol. 282, no. 23, pp. 2220-2226, 1999.

[20] E. Losina, Y. Yazdanpanah, S. Deuffic-Burban et al., "The independent effect of highly active antiretroviral therapy on severe opportunistic disease incidence and mortality in HIVinfected adults in Côte d'Ivoire," Antiviral Therapy, vol. 12, no. 4, pp. 543-551, 2007.

[21] M. Egger, M. May, G. Chêne et al., "Prognosis of HIV-1infected patients starting highly active antiretroviral therapy: a collaborative analysis of prospective studies," The Lancet, vol. 360, no. 9327, pp. 119-129, 2002.

[22] "CD4 cell count and the risk of AIDS or Death in HIV infected adults on combination antiretroviral therapy with a suppressed viral load: a longitudinal cohort study from COHERE," PLoS Medicine, vol. 9, no. 3, Article ID e1001194, 2012.

[23] J. Seddon and S. Bhagani, "Antimicrobial therapy for the treatment of opportunistic infections in HIV/AIDS patients: a critical appraisal," HIV/AIDS: Research and Palliative Care, vol. 3, pp. 19-33, 2011.

[24] J. Aberg and W. Powderly, "HIV: primary and secondary prophylaxis for opportunistic infections," Clinical Evidence, vol. 6, article 908, 2010.

[25] J. D. Campbell, D. Moore, R. Degerman et al., "HIV-infected ugandan adults taking antiretroviral therapy with CD4 counts $>200$ cells $/ \mu \mathrm{L}$ who discontinue cotrimoxazole prophylaxis have increased risk of malaria and diarrhea," Clinical Infectious Diseases, vol. 54, no. 8, pp. 1204-1211, 2012.

[26] W. M. El-Sadr, R. Luskin-Hawk, T. M. Yurik et al., "A randomized trial of daily and thrice-weekly trimethoprim- sulfamethoxazole for the prevention of Pneumocystis carinii pneumonia in human immunodeficiency virus-infected persons," Clinical Infectious Diseases, vol. 29, no. 4, pp. 775-783, 1999. 


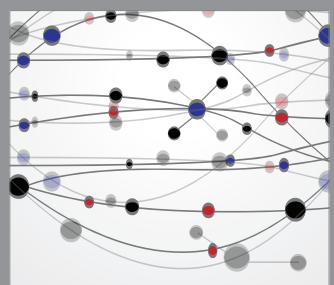

The Scientific World Journal
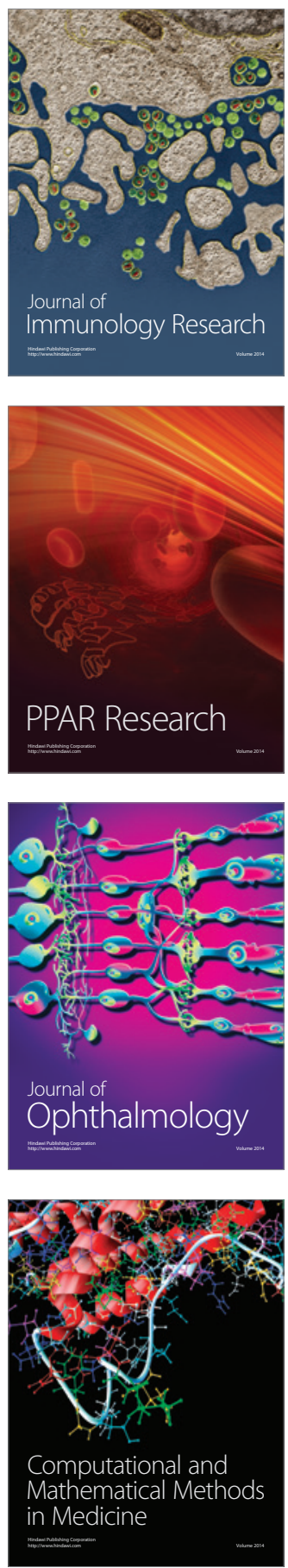

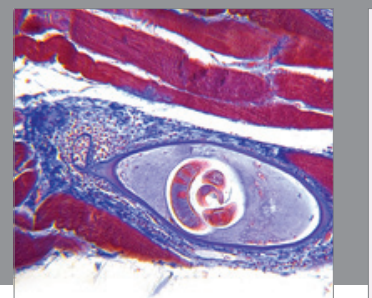

Gastroenterology

Research and Practice
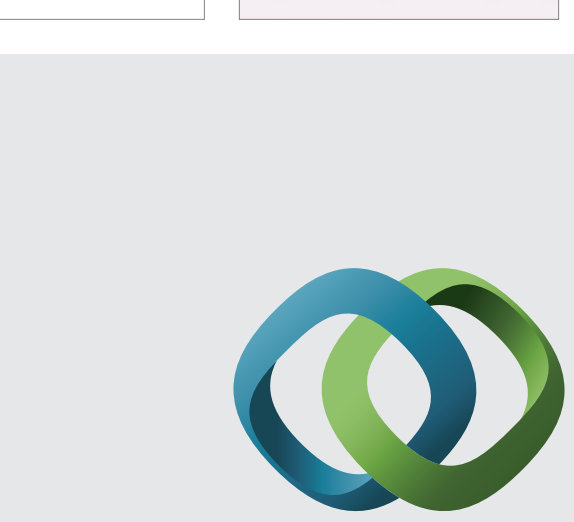

\section{Hindawi}

Submit your manuscripts at

http://www.hindawi.com
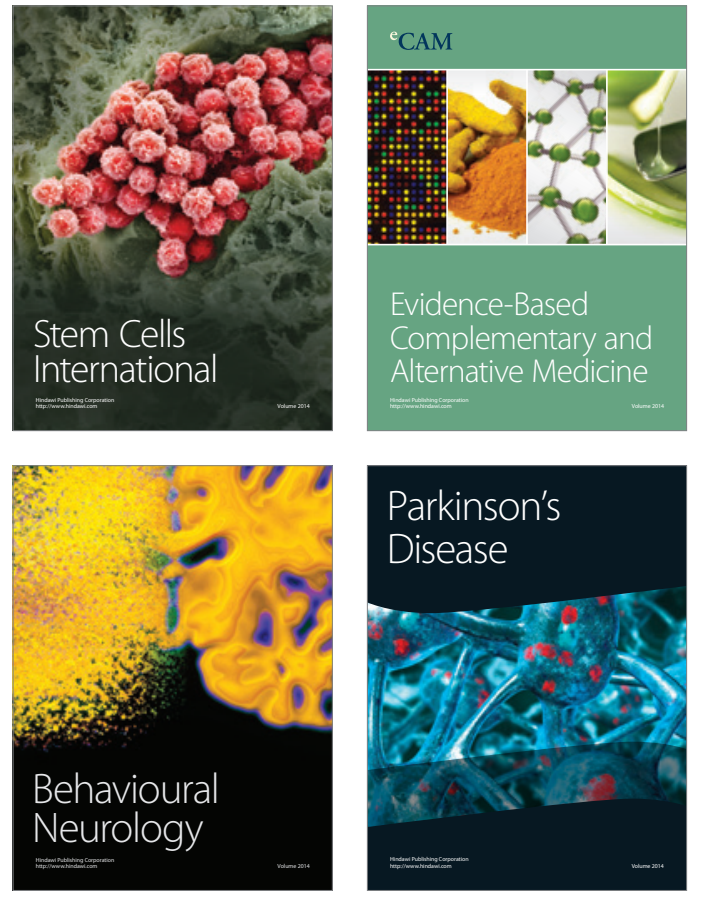
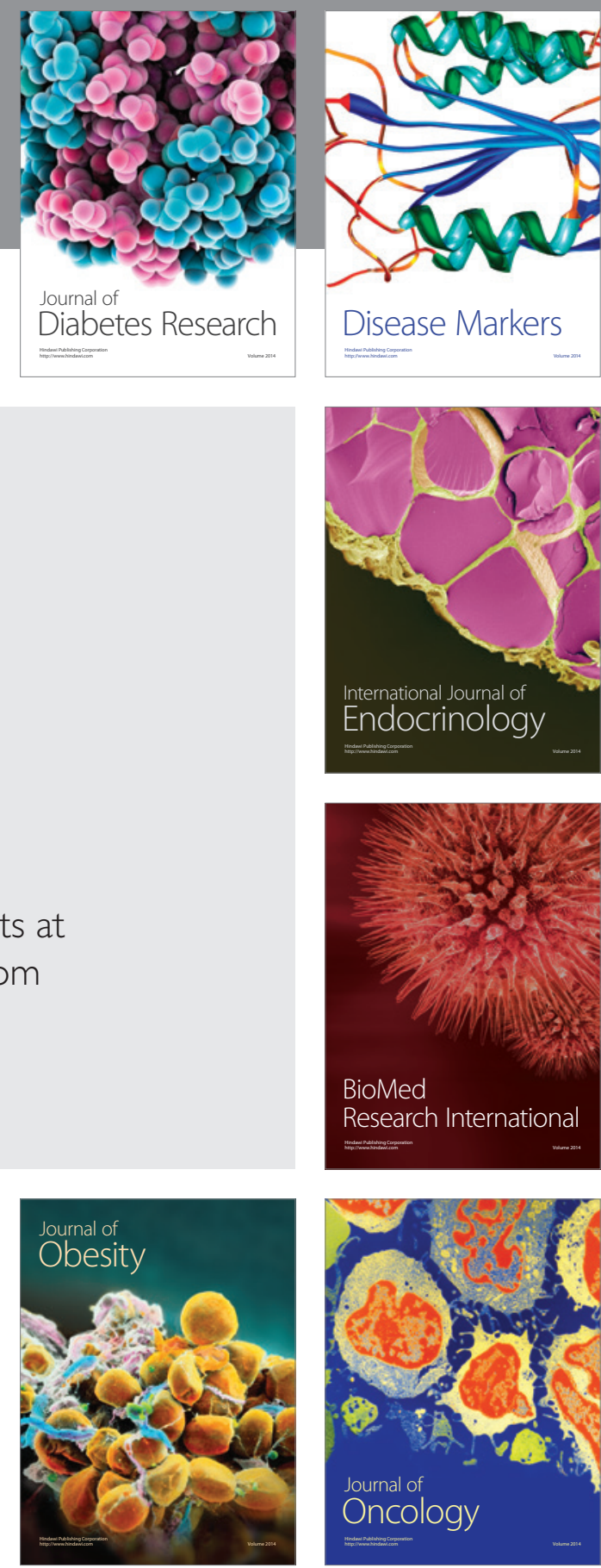

Disease Markers
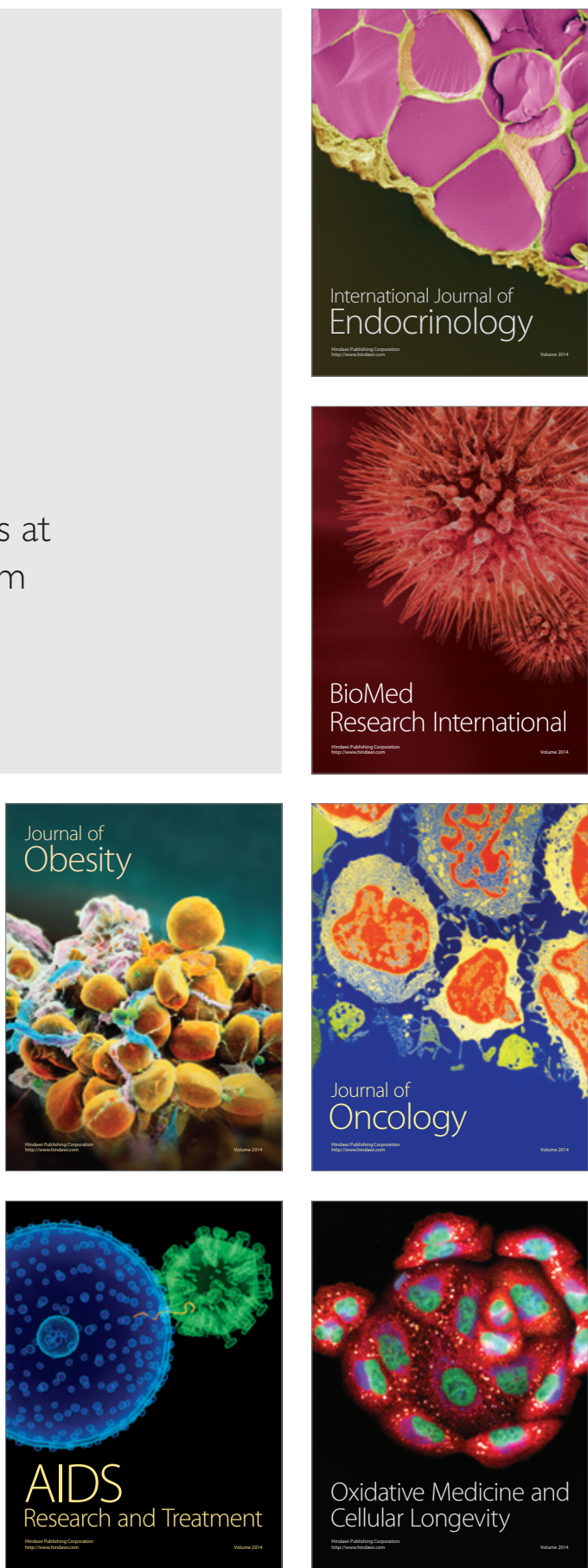